\title{
Importância do conhecimento tradicional no usso de plantas medicinais em Buritis, MG, Brasil
}

\author{
Importance of traditional knowledge in the use of medicinal plants in Buritis, MG, Brazil
}

Bruno Henrique Ferrão ${ }^{* 1}$, Helaine Barros de Oliveira ${ }^{2}$, Renata de Fátima Molinari ${ }^{1}$, Michelle Bicalho Teixeira ${ }^{1}$, Gleide Gatti Fontes ${ }^{3}$, Marilane de Oliveira Fani Amaro ${ }^{3}$, Marcelo Barcellos da Rosa ${ }^{4}$ e Camilo Amaro de Carvalho ${ }^{3}$

\begin{abstract}
${ }^{1}$ Departamento de Farmácia, União de Ensino Superior de Viçosa, UNIVIÇOSA, Viçosa, MG, Brasil ${ }^{2}$ Instituto Federal Sul de Minas Gerais (IFSMG- Campus Muzambinho), Muzambinho, MG, Brasil ${ }^{3}$ Departamento de Medicina e Enfermagem, Universidade Federal de Viçosa, UFV, Viçosa, MG, Brasil ${ }^{4}$ Departamento de Química, Universidade Federal de Santa Maria - UFSM, Santa Maria, RS, Brasil
\end{abstract}

\section{Resumo}

O objetivo dessa pesquisa foi verificar o conhecimento e motivo do uso, assim como meios de obtenção e formas de utilização das plantas medicinais na cidade de Buritis, MG. Os dados da pesquisa foram coletados entre os meses de janeiro e julho de 2011. Baseado em um questionário semi-estruturado, 393 moradores da cidade de Buritis foram entrevistados. Destes, 91\% afirmaram conhecer e utilizar as plantas medicinais, sendo a maioria (64\%) mulheres. A faixa etária predominante foi 21-40 anos (50\%). O principal motivo para utilização das plantas se dá pela tradição familiar (77\%). A parte da planta mais utilizada nas preparações caseiras foi a folha; a forma de preparo mais utilizada foi a infusão; a maioria adquire suas plantas medicinais no próprio quintal. Conclui-se que o uso de plantas medicinais, no município estudado, é tradicional, porém este conhecimento está desaparecendo entre as novas gerações. Assim, este estudo contribui para o resgate do conhecimento e cultura da população pesquisada. Logo, como um dos objetivos de um trabalho etnofarmacológico é a devolução dos resultados da pesquisa para a comunidade, o mesmo será feito através de palestras e cartilhas nas escolas para favorecer o processo de conscientização sobre a importância da biodiversidade do Cerrado.

Palavras-chave: Etnofarmacologia, Cerrado, plantas medicinais, Buritis.

\begin{abstract}
The objective of this research was to determine the knowledge and reason for use, as well as means of obtaining and uses of medicinal plants in the city of Buritis, MG. The survey data were collected between January and July 2011. Based on a semi-structured questionnaire, 393 residents in Buritis were interviewed. Of these, 91\% claimed to know and use medicinal plants, the majority (64\%) women. The predominant age group was 21-40 years ( 50\%). The main reason for the use of plants is by family tradition (77\%). The part of the plant most used in homemade preparations was the sheet, the most widely used form of preparation was infused, the majority acquires medicinal plants in their own backyard. We conclude that the use of medicinal plants in the municipality studied, is traditional, but this knowledge is disappearing among the younger generations. Thus, this study contributes to the rescue of the knowledge and culture of the population studied. As soon as one of the goals of an ethnopharmacological work is the return of research results to the community, the same will be done through lectures and textbooks in schools to assist with the process of awareness about the importance of biodiversity of the Cerrado.
\end{abstract}

Keywords: Ethnopharmacology, Cerrado, medicinal plants, Buritis.

\footnotetext{
* brunohferrao@yahoo.com.br

Recebido: 20/03/2014 Aceito: 20/03/2014
} 


\section{Introdução}

A história da humanidade é acompanhada pela utilização de plantas medicinais que exercem papel significativo na terapêutica mundial (PIRONDO, et al., 2011). A totalidade de recursos naturais existentes no planeta ainda está muito longe de ser plenamente conhecida e entendida pelo homem (CUASSOLO, et al., 2010). No Brasil, apesar da sua imensa diversidade vegetal, pouco se tem feito para estudar o seu potencial como fonte de novas drogas (CAMPESATO, 2005).

$\mathrm{O}$ conhecimento é tradicional quando referente àquele transmitido ao longo das gerações de um determinado povo, podendo fornecer dados importantes para novas pesquisas científicas sobre as propriedades terapêuticas das plantas (VENDRUSCOLO \& MENTZ, 2006).

A etnofarmacologia é um ramo da farmacologia e tem sido definida como o estudo das interações humanas com as plantas (CRESPO, 2010) e neste contexto ela possui a missão de resgatar esse conhecimento, a fim de melhor entender e aprimorar as relações do homem com os recursos vegetais (PATWARDHAN, 2005).

O conhecimento etnofarmacológico é um saber alicerçado na vivência dos indivíduos, nas suas relações pessoais, sociais e também com o ambiente. Pode-se afirmar que o conhecimento tradicional é o resultado da integração de uma população com o meio ambiente e suas descobertas, o que justifica sua riqueza e diversidade (RODRÍGUEZ \& ROBINEAU-GERMOSÉN, 2009).

Todas as plantas são potencialmente capazes de sintetizar metabólitos secundários, com atividade biológica. No entanto, essa característica é mais comum entre as plantas selvagens, que, ao longo do seu ciclo evolutivo, desenvolveram mecanismos de adaptação em seu meio ambiente nativo (OLIVEIRA, et al., 2009).

O Cerrado representa o segundo maior bioma do Brasil, considerado uma savana tropical ocupa cerca de dois milhões de $\mathrm{km} 2$ do território nacional, abrange dez estados e é superado apenas pela floresta amazônica. A característica geral do clima é quente e chuvoso no verão e seco no inverno (SANO, et al., 2008).

Mesmo sendo um ecossistema de índice pluviométrico baixo e de paisagem agressiva, possui cerca de dez mil espécies de plantas (ABRÃO, 2010), sendo muitas endêmicas, algumas com valor econômico como fonte alimentícia, madeireira e melífera (MELO, 2011), além de muitas plantas com potencial medicinal desconhecidas pela comunidade científica (SOUZA \& FELFILI, 2006).

Todavia, esta riqueza contrapõe-se a rapidez com que este bioma é devastado (MELO, 2011). Segundo Sawyer (2009), no Cerrado, o desmatamento anual pode ser duas ou três vezes maior que na Amazônia, sendo que neste bioma ainda não há nenhum programa ou política de controle do desmatamento, já Machado et al. (2004), afirmam que se atuais perdas de áreas nativas permanecerem, o Cerrado deverá ser totalmente destruído em 2030.
A acelerada destruição da biodiversidade do Cerrado representa uma perda do conhecimento adquirido por muito tempo, esta perda pode ser comparada a uma "queima de biblioteca", sendo assim a criação de projetos e áreas de proteção torna-se cada vez mais necessária, não somente pelo poder público, mas por toda a sociedade (SOUZA \& FELFILI, 2006).

Muitos pesquisadores já reconhecem a carência de pesquisas com objetivos de resgatar a vasta gama de informações sobre o uso medicinal de plantas e destacase essa carência principalmente no Cerrado brasileiro (ELISABETSKY \& SOUZA, 2004). Entretanto, a acelerada destruição da biodiversidade do Cerrado representa uma perda do conhecimento adquirido por muito tempo (SOUZA \& FELFILI, 2006).

Neste sentido, este trabalho tem como objetivo fazer um resgate do conhecimento popular tradicional, através de um levantamento etnobotânico e etnofarmacológico, levando-se em consideração que um dos requisitos para implantação de programas de conservação é o conhecimento sobre a diversidade biológica existente na região, além de proporcionar uma conscientização da importância da biodiversidade local para a sobrevivência de muitos membros da comunidade entrevistada, seja pelo comércio de plantas medicinais, seja por possuírem as plantas medicinais como única alternativa terapêutica de tratamento.

\section{Material e métodos}

O levantamento etnobotânico e etnofarmacológico, foi realizado no município de Buritis, região Noroeste de Minas Gerais, criado pela lei 2764 de 30 de dezembro de 1962 e instalado em 01 de março de 1963, pertencente ao bioma do Cerrado. A cidade possui uma área territorial de $5.219 \mathrm{~km} 2$ e se encontra nas coordenadas geográficas: $15^{\circ} 37^{\prime} 22,10 \mathrm{~S}$ e $46^{\circ} 25^{\prime}$ 24,98' $\mathrm{O}$, distando $722 \mathrm{~km}$ da capital do Estado e $220 \mathrm{~km}$ da capital Federal (Brasília). Segundo dados do censo IBGE (2010) a população em 2010 foi de 22.729 habitantes, correspondendo a uma densidade demográfica de 4,11 habitantes $/ \mathrm{km}^{2}$.

A pesquisa ocorreu nos meses de janeiro, fevereiro, junho e julho de 2011, por meio de aplicação de questionários semi-estruturados. $\mathrm{O}$ projeto foi aprovado, sob o protocolo no 00065/2011-I, pelo Comitê de Ética em Pesquisa da Faculdade de Ciências Biológicas e da Saúde - FACISA/UNIVIÇOSA. A participação na pesquisa foi voluntária e todas as condições e características da pesquisa foram esclarecidas antes da realização da entrevista, segundo a Resolução 196/96 do Conselho Nacional de Ética em Pesquisa - CONEP, que normati$\mathrm{za}$ as pesquisas envolvendo seres humanos. Anexo ao questionário, havia o termo de consentimento livre e esclarecido, no qual aqueles que aceitaram participar assinaram para comprovar a sua voluntariedade.

Os questionários semi-estruturados constaram de 
dados gerais dos entrevistados (idade, sexo, grau de instrução), informações a respeito das plantas (motivo da utilização da planta, sua utilidade, parte utilizada, modo de uso), além de permitir aos participantes expressarem suas opiniões e pontos de vista.

A amostra deste estudo foi constituída por 393 pessoas, sendo calculada segundo as equações I e II para amostragem, descritas por Carvalho, 2005.

Equação I: $n_{0}=1 /\left(\mathrm{E}_{0}\right)^{2}$

Equação II: $n=\mathrm{N} \times n_{0} / \mathrm{N}+n_{0}$

Sendo que:

$n_{0}=$ primeira aproximação do tamanho da amostra

$\mathrm{E}_{0}=$ erro amostral tolerável (estipulado para $5 \%$ )

$N=$ tamanho da população (aproximadamente 23 mil)

$n$ = tamanho da amostra

Todas as citações dos entrevistados foram analisadas e após a identificação das plantas, todas encontradas com auxílio de três informantes (raizeiros) foram herborizadas em acervo pessoal, somando um total de 88 exsicatas.

A identificação das plantas relatadas foi realizada por meio de comparação das exsicatas e nomes populares com imagens para comparações, consulta a especialistas e literatura especializada como livros e trabalhos científicos sobre plantas medicinais (LORENZI \& MATOS, 2002; ABRÃO, 2010).

Os resultados obtidos foram submetidos à análise estatística descritiva por meio de freqüência relativa.

\section{Resultados e discussão}

Do total de 393 indivíduos entrevistados, 359 (91\%) afirmaram fazer uso de plantas para tratamento de alguma enfermidade e/ou possuem conhecimento acerca das mesmas. Destes, 231 (64\%) eram do gênero feminino e $128(36 \%)$ do gênero masculino.

Diante desses resultados, pode-se levantar a possibilidade dos mesmos terem sido influenciados pelo horário em que as pesquisas foram realizadas (entre $09 \mathrm{~h} 00 \mathrm{~min}$ e 18h00min), uma vez que ainda há um predomínio de homens trabalhando fora e mulheres em casa, nas pequenas cidades brasileiras. No entanto, deve-se ressaltar que comumente os levantamentos etnofarmacológicos revelam maior freqüência de mulheres com este tipo de conhecimento, tanto que dados semelhantes já foram relatados por diversos autores como, Souza, et al., (2010), Calabria, et al., (2008), Arnous, et al., (2005), entre outros.

Segundo Rodrigues \& Casali (2002), as mulheres são grandes detentoras do conhecimento sobre as plantas medicinais e têm importante papel no processo de transmissão.

O desempenho das atividades cotidianas pode ser um fator responsável pela diferenciação do conhecimento entre os gêneros. A mulher geralmente é a responsável pelo cultivo das plantas medicinais e pelos cuidados aos familiares quando enfermos, portanto seu conhecimento é mais abrangente sobre as espécies "domesticadas", enquanto entre os homens verifica-se maior conhecimento sobre as plantas nativas (ALMEIDA, et al., 2009).

Foram entrevistados 393 indivíduos, em que 10,7\% apresentavam-se em faixa etária abaixo de 20 anos, $47,8 \%$ entre 21 a 40 anos, $26,5 \%$ entre 41 e 60 e $15,0 \%$ acima de 60 anos.

Observa-se que a parte da população entrevistada que mais detêm o conhecimento sobre as plantas medicinais encontra-se acima de 60 anos $(100 \%$ dos indivíduos nessa faixa afirmaram possuir conhecimento acerca de plantas medicinais), e esse percentual de conhecimento diminui gradativamente com a redução da faixa etária dos indivíduos (Tabela 1). De acordo com outros autores, a faixa etária mais conhecedora do uso de plantas medicinais também tem sido os entrevistados acima de 60 anos, deparando-se com um resultado similar a esta pesquisa, como no estudo de Rodrigues e Carvalho (2001) onde a faixa de 56 a 72 anos é predominante e 61 a 70 no estudo de Calabria et al. (2008).

Um dado relevante foi a "quebra" no repasse do conhecimento na faixa etária inferior a 20 anos. Em todas as faixas observou-se no mínimo $96 \%$ de prevalência de indivíduos conhecedores sobre o número total de indivíduos entrevistados na faixa etária, no entanto, na faixa etária mais jovem o percentual reduziu para apenas 38\% de indivíduos afirmando possuir conhecimento sobre plantas medicinais (Tabela 1). Tal resultado indica que o conhecimento está sendo perdido nas novas gerações, sendo este fato prejudicial porque pode gerar a extinção de um conhecimento adquirido ao longo de muitas gerações na região. Gama \& Silva (2006) verificaram em seu estudo na cidade de São Paulo, que os idosos são grandes conhecedores e recorrem freqüentemente a fitoterapia como fonte de tratamento.

Verificou-se que dentre todos os entrevistados com conhecimento acerca de plantas, apenas $4 \%$ eram jovens, o que aponta para uma possível perda de repasse acerca de tal conhecimento tradicional, o que em um futuro próximo pode acarretar na extinção, em curto espaço de tempo, de um saber único. Neste sentido, levantamentos etnofarmacológicos prestam grande contribuição para o resgate deste tipo de conhecimento e cultura na população pesquisada.

Deve-se ressaltar que alguns fatores do mundo moderno podem ser responsáveis pela perda do conhecimento popular tradicional, tais como as mudanças econômicas e culturais externas, a maior facilidade de acesso aos serviços da medicina moderna e o fato dos membros mais jovens encararem o saber tradicional como sendo inferior (ALMEIDA, et al., 2009). De acordo com WAYLAND (2004), a imagem dos medicamentos alopáticos, veiculadas nos meios de comunicação, é símbolo de modernidade e contrasta com a imagem do recurso terapêutico antigo dos chás. Tais intervenções 
Tabela 1. Relação dos entrevistados que possuem conhecimento por faixa etária.

\begin{tabular}{c|ccc}
\hline Faixa Etária anos & $\begin{array}{c}\text { Número de } \\
\text { Entrevistados Total }\end{array}$ & $\begin{array}{c}\text { Número de } \\
\text { entrevistados } \\
\text { conhecedores por } \\
\text { faixa etária }\end{array}$ & $\%$ * \\
\hline Até 20 & 42 & 16 & $38,09 \%$ \\
21 a 40 & 188 & 182 & $96,80 \%$ \\
41 a 60 & 104 & 102 & $98,08 \%$ \\
Acima de 60 & 59 & 59 & $100 \%$ \\
Total & 393 & 359 & \\
\hline
\end{tabular}

*Percentual de entrevistados conhecedores em suas respectivas idades.

podem causar o fascínio dos jovens pelos medicamentos alopáticos.

Sacramento (1997) complementa que, devido à influência dos meios de comunicação, o saber popular com relação às plantas medicinais passou por um processo de descaracterização nas últimas décadas. A autora ainda alerta que ao seu combate, são necessários cada vez mais trabalhos de resgate do conhecimento popular.

Quando questionados sobre o motivo do uso de plantas medicinais, os principais relatados para o uso dos vegetais foram: tradição familiar $(77 \%)$, por não fazer mal a saúde $(11 \%)$, baixo custo $(6 \%)$, indicação médica (5\%), outros motivos (1\%).

Mosca \& Loiola (2009) mencionaram que, entre os entrevistados de seu levantamento no Rio Grande do Norte, havia uma acentuada influência da tradição familiar, que repassava informações acerca de como utilizar plantas no tratamento das doenças.

As práticas relacionadas ao uso popular de plantas medicinais são transmitidas oralmente de gerações a gerações e os estudos etnofarmacológicos são de suma importância para a preservação deste conhecimento (FALCÃO \& MENEZES, 2003), o qual está em processo de desaparecimento.

Aproximadamente, mais da metade (51\%) dos entrevistados coletam as plantas medicinais nos quintais de suas próprias residências. Resultado bem próximo foi obtido por Brasileiro, et al. (2008), em que a maioria da população amostrada também adquire plantas através de plantações próprias.

Entretanto, a coleta na mata nativa foi a segunda forma de coleta mais citada, atingindo uma freqüência relativa de $38 \%$. Este dado é muito relevante, pois, indica que grande parte da população recorre às plantas oriundas da região para tratar doenças, o que caracteriza o Cerrado como uma importante fonte de remédios naturais para sua população local.
O levantamento amostrou 128 espécies, distribuídas em 55 famílias (Tabela 2). As famílias mais representativas foram, respectivamente, Asteraceae, Lamiaceae, Fabaceae e Rubiaceae. Essas famílias têm sido freqüentemente registradas como as mais abundantes em levantamentos da flora medicinal (PEREIRA, et al., 2007).

Grande parte das plantas medicinais utilizadas na América Latina pertence às famílias Lamiaceae e Asteraceae, que se caracterizam por possuírem elevado número de espécies ricas na categoria de princípios ativos chamada de "óleos essenciais" ou "óleos voláteis". Tal categoria de princípios ativos é responsável por amplo espectro terapêutico, tanto no sistema digestório quanto respiratório (ALMASSY JUNIOR, 2004).

Ao comparar os resultados da Tabela 2 com as descrições das espécies apresentadas na Farmacopéia Brasileira (Brasil, 2010a; Brasil 2010b), verificou-se que apenas 07 destas espécies estão descritas: Cymbopogon citratus Stapf., Psidium guajava L., Stryphnodendron adstringens (Mart.) Coville, Allium sativum L., Achyrocline satureoides (Lam.) DC, Phyllanthus niruri L. e Phyllanthus tenellus Roxb.

Portanto, os resultados deste levantamento sugerem a importância de se resgatar o conhecimento tradicional das plantas medicinais do Cerrado para gerar diversos benefícios como conservar informações que estão sendo perdidas muito rapidamente nas últimas gerações; favorecer o processo de conscientização da importância do Cerrado e sua flora medicinal na população local; direcionar futuras pesquisas em busca de novos produtos naturais com potencial terapêutico com plantas do Cerrado e proporcionar uma ligação das Universidades com populações locais, gerando trocas de diferentes conhecimentos. 
Tabela 2 . Espécies tradicionalmente medicinais mais citadas pela população de Buritis, MG.

\begin{tabular}{|c|c|c|c|c|c|}
\hline $\begin{array}{l}\text { Nome } \\
\text { Popular }\end{array}$ & $\begin{array}{c}\text { Nome } \\
\text { Científico } \\
\end{array}$ & Família & Indicação Popular & $\begin{array}{c}\text { Parte } \\
\text { Utilizada } \\
\end{array}$ & $\begin{array}{l}\text { Modo de } \\
\text { Uso }\end{array}$ \\
\hline Abacate & $\begin{array}{c}\text { Persea americana } \\
\text { Mill. }\end{array}$ & Lauraceae & $\begin{array}{l}\text { Afecções renais, } \\
\text { hipertensão }\end{array}$ & Folha & Decocção \\
\hline Açafrão & Curcuma longa L. & Zingiberaceae & $\begin{array}{c}\text { Problemas hepáticos, } \\
\text { gastrite }\end{array}$ & Rizomas & $\begin{array}{l}\text { Decocção, } \\
\text { maceração }\end{array}$ \\
\hline Agrião & $\begin{array}{l}\text { Nasturtium } \\
\text { officinale R. Br. }\end{array}$ & Brassicaceae & $\begin{array}{l}\text { Expectorante, } \\
\text { antiinflamatório }\end{array}$ & Hastes & $\begin{array}{l}\text { Infusão, } \\
\text { xarope }\end{array}$ \\
\hline Alcachofra & $\begin{array}{c}\text { Cynara scolymus } \\
\text { L. }\end{array}$ & Asteraceae & Hipocolesterolêmica & Folha & Infusão \\
\hline $\begin{array}{c}\text { Alfavaca, } \\
\text { Alfavaquinha }\end{array}$ & $\begin{array}{l}\text { Ocimum basilicum } \\
\text { L. }\end{array}$ & Lamiaceae & Gripe, tosse & Folha & Infusão \\
\hline $\begin{array}{c}\text { Alfavaca, } \\
\text { alfavaca cravo }\end{array}$ & $\begin{array}{c}\text { Ocimum } \\
\text { gratissimum L. }\end{array}$ & Lamiaceae & Gripe & Folha & Infusão \\
\hline Algodão & $\begin{array}{l}\text { Gossypium } \\
\text { hirsutum L. }\end{array}$ & Malvaceae & $\begin{array}{c}\text { Antiinflamatório, } \\
\text { cálculos renais }\end{array}$ & Folha & $\begin{array}{l}\text { Decocção, } \\
\text { suco }\end{array}$ \\
\hline Algodãozinho & $\begin{array}{l}\text { Cochlospermum } \\
\text { regium (Mart. \& } \\
\text { Schr.) pilger. }\end{array}$ & Cochlospermaceae & $\begin{array}{l}\text { Antiinflamatório } \\
\text { urinário e uterino }\end{array}$ & Folha & Decocção \\
\hline Alecrim & $\begin{array}{l}\text { Rosmarinus } \\
\text { officinalis L. }\end{array}$ & Lamiaceae & $\begin{array}{l}\text { Antiinflamatório, } \\
\text { problemas } \\
\text { respiratórios, } \\
\text { hipertensão } \\
\end{array}$ & $\begin{array}{l}\text { Folha, } \\
\text { haste }\end{array}$ & $\begin{array}{l}\text { Decocção, } \\
\text { infusão, } \\
\text { xarope }\end{array}$ \\
\hline Alevante & Mentha spicata L. & Lamiaceae & $\begin{array}{l}\text { Gripe, tosse, } \\
\text { expectorante }\end{array}$ & Folha & Xarope \\
\hline Alho & Allium satioum L. & Liliaceae & $\begin{array}{l}\text { Hipocolesteromiante, } \\
\text { antiinflamatório }\end{array}$ & Fruto & Xarope \\
\hline Amora & Morus nigra L. & Moraceae & $\begin{array}{c}\text { Menopausa, } \\
\text { emagrecer, } \\
\text { hipertensão, } \\
\text { inflamação uterina }\end{array}$ & Folha & Infusão \\
\hline $\begin{array}{c}\text { Amor deixado, } \\
\text { macaé }\end{array}$ & $\begin{array}{c}\text { Leonurus sibiricus } \\
\text { L. }\end{array}$ & Lamiaceae & Dor de barriga & Flor, folha & Infusão \\
\hline Angá, ingá & Inga sp. & Fabaceae & Cicatrização & Cascas & $\begin{array}{l}\text { Decocção e } \\
\text { compressas }\end{array}$ \\
\hline Angélica & $\begin{array}{c}\text { Angelica } \\
\text { archangelica L. }\end{array}$ & Apiaceae & Afecções renais & Raiz & Decocção \\
\hline Angico branco & $\begin{array}{c}\text { Albizia niopoides } \\
\text { (Bentham) } \\
\text { Burkart }\end{array}$ & Mimosoideae & $\begin{array}{c}\text { Afecções pulmonares, } \\
\text { cicatrizante }\end{array}$ & Casca & $\begin{array}{l}\text { Decocção, } \\
\text { maceração }\end{array}$ \\
\hline Araçá & $\begin{array}{l}\text { Psidium araca } \\
\text { Raddi. }\end{array}$ & Myrtaceae & Antidiarréico & Folha & Decocção \\
\hline $\begin{array}{l}\text { Araticum, } \\
\text { articum }\end{array}$ & $\begin{array}{c}\text { Annona crassiflora } \\
\text { Mart. }\end{array}$ & Annonaceae & Antidiarréico, úlceras & Folha, raiz & Decocção \\
\hline Aroeira & $\begin{array}{c}\text { Myracrodruon } \\
\text { urundeuva } \\
\text { Allemao } \\
\end{array}$ & Anacardiaceae & $\begin{array}{c}\text { Afecções urinárias, } \\
\text { coceira, depurativo, } \\
\text { labirintite }\end{array}$ & Entrecasca & $\begin{array}{c}\text { Decocção ou } \\
\text { maceração }\end{array}$ \\
\hline
\end{tabular}


Tabela 2 . Continuação...

\begin{tabular}{|c|c|c|c|c|c|}
\hline $\begin{array}{l}\text { Nome } \\
\text { Popular }\end{array}$ & $\begin{array}{c}\text { Nome } \\
\text { Científico } \\
\end{array}$ & Família & Indicação Popular & $\begin{array}{c}\text { Parte } \\
\text { Utilizada }\end{array}$ & $\begin{array}{l}\text { Modo de } \\
\text { Uso }\end{array}$ \\
\hline Arruda & Ruta graveolens L. & Rutaceae & Cólicas menstruais & Folha & Infusão \\
\hline $\begin{array}{l}\text { Assa peixe, } \\
\text { Assa peixe } \\
\text { branco }\end{array}$ & $\begin{array}{l}\text { Vernonia brasiliana } \\
\text { (L.) Druce }\end{array}$ & Asteraceae & Gripe, bronquite, tosse & Folha & $\begin{array}{l}\text { Decocção e } \\
\text { xarope }\end{array}$ \\
\hline Babosa & Aloe vera $\mathrm{L}$. & Liliaceae & $\begin{array}{l}\text { Câncer, digestivo, } \\
\text { cicatrizante }\end{array}$ & Folha & Compressa \\
\hline Bálsamo & $\begin{array}{l}\text { Cotyledon } \\
\text { orbiculata L. }\end{array}$ & Crassulaceae & $\begin{array}{l}\text { Contusões, feridas na } \\
\text { pele }\end{array}$ & Folha & Compressa \\
\hline Barbatimão & $\begin{array}{l}\text { Stryphnodendron } \\
\text { adstringens } \\
\text { (Mart.) Coville }\end{array}$ & Fabaceae & $\begin{array}{c}\text { Cicatrizante, } \\
\text { antibiótico, anti- } \\
\text { séptico, inflamação } \\
\text { uterina }\end{array}$ & Entrecasca & Decocção \\
\hline Baru & $\begin{array}{l}\text { Dipteryx alata } \\
\text { Vog. }\end{array}$ & Leguminosae & $\begin{array}{l}\text { Tônico, gripe, tosse, } \\
\text { artrose, gastrite, } \\
\text { anemia }\end{array}$ & $\begin{array}{l}\text { Entrecasca, } \\
\text { folha e } \\
\text { semente }\end{array}$ & $\begin{array}{c}\text { Decocção, } \\
\text { xarope e } \\
\text { consumo da } \\
\text { semente }\end{array}$ \\
\hline $\begin{array}{c}\text { Batata de } \\
\text { purga }\end{array}$ & $\begin{array}{c}\text { Ipomoea operculata } \\
\text { Mart. }\end{array}$ & Convolvulaceae & Verminoses, purgativa & Raiz & Infusão \\
\hline Berinjela & $\begin{array}{c}\text { Solanum } \\
\text { melongena } \mathrm{L} .\end{array}$ & Solanaceae & Diabetes & Fruto & Suco \\
\hline $\begin{array}{l}\text { Boldo, sete } \\
\text { dores }\end{array}$ & $\begin{array}{l}\text { Plectranthus } \\
\text { barbantus } \\
\text { Andrews }\end{array}$ & Lamiaceae & $\begin{array}{l}\text { Digestivo, afecções } \\
\text { hepáticas, afecções } \\
\text { estomacais, gastrite }\end{array}$ & Folha & $\begin{array}{l}\text { Infusão, } \\
\text { maceração, } \\
\text { suco }\end{array}$ \\
\hline $\begin{array}{l}\text { Boldo, Boldo } \\
\text { da China, } \\
\text { Boldo japonês }\end{array}$ & $\begin{array}{c}\text { Vernonia } \\
\text { condensata Baker }\end{array}$ & Asteraceae & $\begin{array}{l}\text { Digestivo, afecções } \\
\text { hepáticas, afecções } \\
\text { estomacais, náuseas }\end{array}$ & Folha & $\begin{array}{l}\text { Infusão, } \\
\text { maceração, } \\
\text { suco }\end{array}$ \\
\hline Bugre & $\begin{array}{c}\text { Rudgea } \\
\text { virbunoides } \\
\text { (Cham) Benth. }\end{array}$ & Rubiaceae & $\begin{array}{l}\text { Anti reumático, } \\
\text { cálculo renal, } \\
\text { afecções de bexiga, } \\
\text { emagrecimento }\end{array}$ & Folha & Decocção \\
\hline Buriti & $\begin{array}{l}\text { Mauritia flexuosa } \\
\text { L.f. }\end{array}$ & Arecaceae & $\begin{array}{c}\text { Vermífugo, } \\
\text { cicatrizante, dores na } \\
\text { coluna }\end{array}$ & Raiz & $\begin{array}{l}\text { Decocção, } \\
\text { alcoolaturas }\end{array}$ \\
\hline Cagaiteira & $\begin{array}{c}\text { Eugenia } \\
\text { dysenterica DC. }\end{array}$ & Myrtaceae & $\begin{array}{l}\text { Laxante, icterícia, } \\
\text { afecções renais }\end{array}$ & $\begin{array}{l}\text { Folha, } \\
\text { fruto }\end{array}$ & $\begin{array}{l}\text { Decocção, } \\
\text { suco }\end{array}$ \\
\hline Caju & $\begin{array}{l}\text { Anacardium } \\
\text { occidentale } \mathrm{L} \text {. }\end{array}$ & Anacardiaceae & Feridas na boca & Entrecasca & $\begin{array}{l}\text { Decocção } \\
\text { (gargarejo) }\end{array}$ \\
\hline Calunga & $\begin{array}{c}\text { Simaba ferruginea } \\
\text { St. Hil }\end{array}$ & Simaroubaceae & $\begin{array}{l}\text { Cálculos biliares, } \\
\text { afecções hepáticas e } \\
\text { digestivas }\end{array}$ & Raiz & $\begin{array}{l}\text { Maceração, } \\
\text { decocção }\end{array}$ \\
\hline Camomila & $\begin{array}{l}\text { Matricaria } \\
\text { chamomila L. }\end{array}$ & Asteraceae & Cólica, calmante & Flor & Infusão \\
\hline $\begin{array}{l}\text { Cana de } \\
\text { macaco }\end{array}$ & $\begin{array}{l}\text { Costus spicatus } \\
\text { (Jacq.) }\end{array}$ & Costaceae & $\begin{array}{l}\text { Cálculo renal, } \\
\text { Diurético }\end{array}$ & Haste & Decocção \\
\hline
\end{tabular}


Tabela 2 . Continuação...

\begin{tabular}{|c|c|c|c|c|c|}
\hline $\begin{array}{l}\text { Nome } \\
\text { Popular }\end{array}$ & $\begin{array}{c}\text { Nome } \\
\text { Científico }\end{array}$ & Família & Indicação Popular & $\begin{array}{c}\text { Parte } \\
\text { Utilizada }\end{array}$ & $\begin{array}{l}\text { Modo de } \\
\text { Uso }\end{array}$ \\
\hline Canela & $\begin{array}{c}\text { Cinnamomum } \\
\text { zeylanicum Breyn. }\end{array}$ & Lauraceae & Gripe, resfriados & Folha & $\begin{array}{l}\text { Decocção, } \\
\text { inalação }\end{array}$ \\
\hline $\begin{array}{l}\text { Canelinha de } \\
\text { perdiz, pé de } \\
\text { perdiz }\end{array}$ & $\begin{array}{c}\text { Simarouba } \\
\text { versicolor A. St.- } \\
\text { Hil., }\end{array}$ & Simaroubaceae & $\begin{array}{c}\text { Cicatrizante, } \\
\text { Inflamações do útero, } \\
\text { cálculo biliar, cálculo } \\
\text { renal }\end{array}$ & Folha, raiz & Decocção \\
\hline Capim meloso & $\begin{array}{c}\text { Melinis } \\
\text { minutiflora P. } \\
\text { Beauv. }\end{array}$ & Poaceae & Afecções pulmonares & Folha & $\begin{array}{l}\text { Infusão, } \\
\text { xarope }\end{array}$ \\
\hline $\begin{array}{l}\text { Capim santo, } \\
\text { capim cidreira, } \\
\text { capim limão, } \\
\text { erva cidreira }\end{array}$ & $\begin{array}{l}\text { Cymbopogon } \\
\text { citratus (DC) } \\
\text { Stapf. }\end{array}$ & Poaceae & $\begin{array}{l}\text { Calmante, insônia, } \\
\text { analgésico, resfriado, } \\
\text { hipotensor }\end{array}$ & Folha & $\begin{array}{l}\text { Infusão, } \\
\text { xarope }\end{array}$ \\
\hline Capitão & $\begin{array}{c}\text { Terminalia } \\
\text { argentea Mart. \& } \\
\text { Zucc. }\end{array}$ & Combretaceae & Tosse, gripe & Casca & Decocção \\
\hline Carrapicho & $\begin{array}{l}\text { Acanthospermum } \\
\text { australe (Loefl.) } \\
\text { Kuntze }\end{array}$ & Asteraceae & Dores na costas & Toda & Decocção \\
\hline Carrapicho & $\begin{array}{l}\text { Acanthospermum } \\
\text { hispidum DC. }\end{array}$ & Asteraceae & Febre, vermífugo & Toda & Decocção \\
\hline $\begin{array}{l}\text { Cariru de } \\
\text { porco }\end{array}$ & $\begin{array}{l}\text { Amaranthus } \\
\text { hybridus L. }\end{array}$ & Amaranthaceae & Febre & Raiz & Decocção \\
\hline Carqueja & $\begin{array}{l}\text { Baccharis trimera } \\
\text { (Less.) DC. }\end{array}$ & Asteraceae & $\begin{array}{l}\text { Afecções hepáticas, } \\
\text { diurético, obesidade }\end{array}$ & Folha & Infusão \\
\hline Carobinha & $\begin{array}{c}\text { Jacaranda } \\
\text { decurrens Cham. }\end{array}$ & Bignoniaceae & Laxante, diurética & Raiz & Decocção \\
\hline Chá verde & $\begin{array}{c}\text { Camelia sinensis } \\
\text { L. }\end{array}$ & Theaceae & Diurético & Flor & Infusão \\
\hline $\begin{array}{l}\text { Chapéu de } \\
\text { couro }\end{array}$ & $\begin{array}{c}\text { Echinodorus } \\
\text { macrophyllus } \\
\text { (Kunth) Micheli }\end{array}$ & Alismataceae & $\begin{array}{l}\text { Afecções renais, } \\
\text { erupções cutâneas }\end{array}$ & $\begin{array}{l}\text { Folha, } \\
\text { rizoma }\end{array}$ & Decocção \\
\hline Chuchu & $\begin{array}{l}\text { Sequium edule } \\
\text { (Jacq.) Sw. }\end{array}$ & Cucurbitaceae & Diurético e hipotensor & Folha & Infusão \\
\hline Cipó podre & Não identificada & Não identificada & Analgésico & $\begin{array}{c}\text { Folha, } \\
\text { casca }\end{array}$ & Infusão \\
\hline Confrei & $\begin{array}{l}\text { Symphytum } \\
\text { officinale L. }\end{array}$ & Boraginaceae & $\begin{array}{l}\text { Cicatrizante, } \\
\text { antiinflamatório }\end{array}$ & Folha & $\begin{array}{l}\text { Compressa, } \\
\text { infusão }\end{array}$ \\
\hline Copaíba & $\begin{array}{c}\text { Copaifera } \\
\text { langsdorffii, Mart. }\end{array}$ & Caesalpiniaceae & $\begin{array}{c}\text { Cicatrizante, afecções } \\
\text { respiratórias }\end{array}$ & $\begin{array}{l}\text { Óleo e/ou } \\
\text { resina do } \\
\text { caule }\end{array}$ & $\begin{array}{l}\text { Óleo in } \\
\text { natura, } \\
\text { xarope, } \\
\text { decocção }\end{array}$ \\
\hline
\end{tabular}


Tabela 2 . Continuação...

\begin{tabular}{|c|c|c|c|c|c|}
\hline $\begin{array}{c}\text { Nome } \\
\text { Popular }\end{array}$ & $\begin{array}{c}\text { Nome } \\
\text { Científico }\end{array}$ & Família & Indicação Popular & $\begin{array}{c}\text { Parte } \\
\text { Utilizada }\end{array}$ & $\begin{array}{c}\text { Modo de } \\
\text { Uso }\end{array}$ \\
\hline $\begin{array}{l}\text { Cordão de } \\
\text { frade }\end{array}$ & $\begin{array}{c}\text { Leonotis } \\
\text { nepetaefolia (L.) } \\
\text { R. Br. }\end{array}$ & Lamiaceae & Asma & Folha & Decocção \\
\hline Crista de galo & $\begin{array}{l}\text { Heliotropium } \\
\text { indicum L. }\end{array}$ & Boraginaceae & Amenorréia & Folha & Decocção \\
\hline $\begin{array}{l}\text { Dorme dorme, } \\
\text { dorme maria }\end{array}$ & Mimosa pudica L. & Mimosaceae & Afecções hepáticas & Raiz & Decocção \\
\hline $\begin{array}{l}\text { Douradinha } \\
\text { do campo }\end{array}$ & Palicourea coriacea & Rubiaceae & $\begin{array}{l}\text { Afecções renais, } \\
\text { doenças venéreas }\end{array}$ & Folha & Decocção \\
\hline $\begin{array}{l}\text { Embaúba, } \\
\text { Umbaúba }\end{array}$ & $\begin{array}{c}\text { Cecropia } \\
\text { pachystachya } \\
\text { Willd. }\end{array}$ & Moraceae & $\begin{array}{c}\text { Gripe, expectorante, } \\
\text { bronquite, anti- } \\
\text { hipertensivo }\end{array}$ & Folha & $\begin{array}{l}\text { Decocção, } \\
\text { xarope }\end{array}$ \\
\hline $\begin{array}{l}\text { Emburana, } \\
\text { Imburana }\end{array}$ & $\begin{array}{c}\text { Amburana } \\
\text { cearensis } \\
\text { (Allemão) A. C. } \\
\text { Sm. }\end{array}$ & Fabaceae & Anti reumático, gripe & Casca & $\begin{array}{l}\text { Decocção, } \\
\text { maceração }\end{array}$ \\
\hline $\begin{array}{l}\text { Erva cidreira, } \\
\text { erva cidreira } \\
\text { de arbusto }\end{array}$ & $\begin{array}{l}\text { Lippia alba (Mill) } \\
\text { N. E. Brown. }\end{array}$ & Verbenaceae & $\begin{array}{l}\text { Calmante, insônia, } \\
\text { relaxante, hipotensora }\end{array}$ & Folha & Infusão \\
\hline $\begin{array}{l}\text { Erva cidreira, } \\
\text { melissa }\end{array}$ & $\begin{array}{l}\text { Melissa officinalis } \\
\text { L. }\end{array}$ & Lamiaceae & Calmante, resfriados & Folha & Infusão \\
\hline Erva tostão & $\begin{array}{c}\text { Boerhavia diffusa } \\
\text { L. }\end{array}$ & Nyctaginaceae & Afecções hepáticas & Toda & Decoção, \\
\hline Eucalipto & Eucaliptus sp. & Myrtaceae & $\begin{array}{c}\text { Afecções das vias } \\
\text { respiratórias }\end{array}$ & Folha & $\begin{array}{l}\text { Infusão, } \\
\text { inalação }\end{array}$ \\
\hline Favela & $\begin{array}{l}\text { Dimorphandra } \\
\text { mollis Benth. }\end{array}$ & Caesalpiniaceae & $\begin{array}{l}\text { Cicatrizante, } \\
\text { queimaduras }\end{array}$ & $\begin{array}{l}\text { Casca, raiz, } \\
\text { folha }\end{array}$ & Decocção \\
\hline Fedegoso & $\begin{array}{l}\text { Senna corymbosa } \\
\text { (Lam.) H.S. Irwin } \\
\text { \& Barneby }\end{array}$ & Fabaceae & Gripe & Raiz & Decocção \\
\hline Feijão andu & $\begin{array}{l}\text { Cajanus cajan (L.) } \\
\text { Millsp. }\end{array}$ & Fabaceae & Dores na coluna & Folha & Decocção \\
\hline Figueira & Ficus carica L. & Moraceae & Tosse & Folha & Decocção \\
\hline $\begin{array}{l}\text { Folha da } \\
\text { fortuna }\end{array}$ & $\begin{array}{l}\text { Bryophillum } \\
\text { pinnatum } \\
\text { (Lam.) Oken }\end{array}$ & Crassulaceae & $\begin{array}{c}\text { Gastrite, inflamações, } \\
\text { gripe }\end{array}$ & Folha & Decocção \\
\hline $\begin{array}{c}\text { Funcho, erva } \\
\text { doce }\end{array}$ & $\begin{array}{l}\text { Foeniculum } \\
\text { vulgare Mill. }\end{array}$ & Apiaceae & $\begin{array}{c}\text { Calmante, } \\
\text { cólicas em bebês }\end{array}$ & Folha & Infusão \\
\hline Gariroba & $\begin{array}{c}\text { Eugenia variabilis } \\
\text { M. }\end{array}$ & Mirtaceae & Diarréia & Folha & Infusão \\
\hline Gengibre & $\begin{array}{l}\text { Zingiber officinale } \\
\text { Roscoe }\end{array}$ & Zingiberaceae & Gripe, tosse & Rizoma & $\begin{array}{c}\text { Decocção, } \\
\text { xarope }\end{array}$ \\
\hline
\end{tabular}


Tabela 2 . Continuação...

\begin{tabular}{|c|c|c|c|c|c|}
\hline $\begin{array}{l}\text { Nome } \\
\text { Popular }\end{array}$ & $\begin{array}{c}\text { Nome } \\
\text { Científico } \\
\end{array}$ & Família & Indicação Popular & $\begin{array}{c}\text { Parte } \\
\text { Utilizada }\end{array}$ & $\begin{array}{l}\text { Modo de } \\
\text { Uso }\end{array}$ \\
\hline Gervão & $\begin{array}{l}\text { Stachytarpheta } \\
\text { cayennensis } \\
\text { (Rich.) Vahl. }\end{array}$ & Verbenaceae & Gripe, pneumonia & Ramo & Infusão \\
\hline Goiaba & $\begin{array}{l}\text { Psidium guajava } \\
\text { L. }\end{array}$ & Myrtaceae & Diarréia & Folha & Decocção \\
\hline Gonçalinho & $\begin{array}{c}\text { Casearia sylvestris } \\
\text { Sw. }\end{array}$ & Salicaceae & Gripe, pneumonia & - & - \\
\hline Graviola & $\begin{array}{c}\text { Annona muricata } \\
\text { L. }\end{array}$ & Annonaceae & Câncer, emagrecer & Folha & Decocção \\
\hline Guaco & $\begin{array}{l}\text { Mikania glomerata } \\
\text { Spreng. }\end{array}$ & Asteraceae & $\begin{array}{l}\text { Expectorante, tosse, } \\
\text { gripe }\end{array}$ & Folha & Xarope \\
\hline Guiné, tipi & $\begin{array}{c}\text { Petiveria alliacea } \\
\text { L. }\end{array}$ & Phytolaccaceae & $\begin{array}{l}\text { Dor muscular, anti } \\
\text { reumática }\end{array}$ & Folha, raiz & Compressa \\
\hline $\begin{array}{l}\text { Hortelã, } \\
\text { hortelã } \\
\text { pimenta, }\end{array}$ & $\begin{array}{l}\text { Mentha } \\
\text { piperita }\end{array}$ & Lamiaceae & $\begin{array}{c}\text { Gripe, tosse, } \\
\text { bronquite, vermífugo }\end{array}$ & Folha & $\begin{array}{l}\text { Infusão, } \\
\text { decocção, } \\
\text { xarope }\end{array}$ \\
\hline $\begin{array}{c}\text { Hortelã, } \\
\text { hortelã-gordo }\end{array}$ & $\begin{array}{l}\text { Plectranthus } \\
\text { amboinicus L. }\end{array}$ & Lamiaceae & Gripe, tosse & Folha & Suco, xarope \\
\hline Ingá & Inga edulis Mart. & Fabaceae & Afecções bucais & Folha & Infusão \\
\hline Insulina & Cissus sicyoides L. & Vitaceae & Diabetes & Folha & Suco \\
\hline Ipê roxo & $\begin{array}{l}\text { Tabebuia } \\
\text { avellanedae Lor. } \\
\text { Ex Griseb. }\end{array}$ & Bignoniaceae & $\begin{array}{l}\text { Antiinflamatório, } \\
\text { inflamações da } \\
\text { próstata, câncer, } \\
\text { hipocolesteromiante, } \\
\text { anti reumático }\end{array}$ & $\begin{array}{l}\text { Entre } \\
\text { casca, } \\
\text { folha }\end{array}$ & $\begin{array}{l}\text { Decocção, } \\
\text { maceração }\end{array}$ \\
\hline Ipê amarelo & $\begin{array}{c}\text { Tabebuia aurea } \\
\text { (Silva Manso) } \\
\text { Benth. \& Hook.f. } \\
\text { ex S. Moore }\end{array}$ & Bignoniaceae & Expectorante, gripe & Entre casca & Decocção \\
\hline Jatobá & $\begin{array}{l}\text { Hymenaea } \\
\text { courbaril L. }\end{array}$ & $\begin{array}{l}\text { Caesalpiniaceae } \\
\text { Leguminosae }\end{array}$ & $\begin{array}{c}\text { Afecções pulmonares, } \\
\text { depurativo, diabetes, } \\
\text { úlcera }\end{array}$ & $\begin{array}{l}\text { Casca, } \\
\text { fruto }\end{array}$ & $\begin{array}{c}\text { Suco, } \\
\text { decocção, } \\
\text { xarope }\end{array}$ \\
\hline Jenipapo & $\begin{array}{c}\text { Genipa americana } \\
\text { L. }\end{array}$ & Rubiaceae & Gastrite & Casca & Decocção \\
\hline Jurubeba & $\begin{array}{c}\text { Solanum } \\
\text { paniculatum L. }\end{array}$ & Solanaceae & $\begin{array}{c}\text { Afecções hepáticas, } \\
\text { estimulante da } \\
\text { digestão }\end{array}$ & $\begin{array}{l}\text { Folha e } \\
\text { fruto }\end{array}$ & Decocção \\
\hline Lobeira & $\begin{array}{c}\text { Solanum } \\
\text { lycocarpum A. St. } \\
\text { Hil. }\end{array}$ & Solanaceae & Afecções hepáticas & Fruto & Suco \\
\hline Losna & $\begin{array}{c}\text { Artemisia } \\
\text { absinthium L. }\end{array}$ & Asteraceae & $\begin{array}{l}\text { Afecções digestivas e } \\
\text { hepáticas, labirintite }\end{array}$ & Folha & $\begin{array}{l}\text { Maceração, } \\
\text { infusão }\end{array}$ \\
\hline
\end{tabular}


Tabela 2 . Continuação...

\begin{tabular}{|c|c|c|c|c|c|}
\hline $\begin{array}{c}\text { Nome } \\
\text { Popular }\end{array}$ & $\begin{array}{c}\text { Nome } \\
\text { Científico }\end{array}$ & Família & Indicação Popular & $\begin{array}{c}\text { Parte } \\
\text { Utilizada }\end{array}$ & $\begin{array}{l}\text { Modo de } \\
\text { Uso }\end{array}$ \\
\hline Macelinha & $\begin{array}{c}\text { Achyrocline } \\
\text { satureoides (Lam.) } \\
\text { DC }\end{array}$ & Asteraceae & Afecções digestivas & Folha & Infusão \\
\hline Malva & Sida rhombifolia L. & Malvaceae & Antinflamatório & Folha & Infusão \\
\hline Mama cadela & $\begin{array}{l}\text { Brosimum } \\
\text { gaudichaudii } \\
\text { Trécul }\end{array}$ & Moraceae & Vitiligo & Raiz & $\begin{array}{l}\text { Decocção, } \\
\text { compressa }\end{array}$ \\
\hline Mamão & Carica papaya L. & Caricaceae & $\begin{array}{l}\text { Labirintite, tonturas, } \\
\text { hipocolesteremiante }\end{array}$ & Flor & Maceração \\
\hline $\begin{array}{l}\text { Mangabeira, } \\
\text { Mangaba }\end{array}$ & $\begin{array}{c}\text { Hancornia speciosa } \\
\text { Gomes }\end{array}$ & Apocynaceae & Hipertensão & Folha & Decocção \\
\hline Manjericão & $\begin{array}{c}\text { Ocimum basilicum } \\
\text { L. }\end{array}$ & Lamiaceae & Gripe, dor de cabeça & Folha & Infusão \\
\hline Maracujá & $\begin{array}{l}\text { Passiflora alata } \\
\text { Curtis }\end{array}$ & Passifloraceae & Calmante, insônia & $\begin{array}{l}\text { Folha, } \\
\text { fruto }\end{array}$ & Infusão, suco \\
\hline $\begin{array}{l}\text { Marmelo do } \\
\text { cerrado }\end{array}$ & Alibertia sessilis & Rubiaceae & Afecções bucais & $\begin{array}{c}\text { Fruto, } \\
\text { semente }\end{array}$ & Decocção \\
\hline $\begin{array}{c}\text { Mastruz, } \\
\text { Mastruço, } \\
\text { Mentruz, Erva } \\
\text { de santa maria }\end{array}$ & $\begin{array}{l}\text { Chenopodium } \\
\text { ambrosioides L. }\end{array}$ & Chenopodiaceae & $\begin{array}{c}\text { Verminoses, } \\
\text { antiinflamatório, } \\
\text { tônico, cicatrizante }\end{array}$ & $\begin{array}{l}\text { Hastes, } \\
\text { raiz }\end{array}$ & $\begin{array}{l}\text { Infusão, } \\
\text { decoç̧ão, } \\
\text { suco }\end{array}$ \\
\hline Mentrasto & $\begin{array}{l}\text { Argeratum } \\
\text { conyzoides L. }\end{array}$ & Asteraceae & $\begin{array}{l}\text { Cólicas, artrite, } \\
\text { reduzir colesterol }\end{array}$ & Folha & Infusão \\
\hline Mil folhas & $\begin{array}{c}\text { Achillea } \\
\text { millefolium } \mathrm{L} .\end{array}$ & Asteraceae & Analgésico & Hastes & Compressas \\
\hline Milho & Zea mays $L$. & Gramineae & Infecção urinária & $\begin{array}{c}\text { Estigmas } \\
\text { e estiletes } \\
\text { ("cabelo de } \\
\text { milho") } \\
\end{array}$ & Infusão \\
\hline Mutamba & $\begin{array}{c}\text { Guazuma ulmifolia } \\
\text { Lam. }\end{array}$ & Sterculiaceae & Queda de cabelo & Fruto & $\begin{array}{l}\text { Decocto em } \\
\text { óleo para } \\
\text { aplicação } \\
\text { tópica }\end{array}$ \\
\hline Pacari & $\begin{array}{l}\text { Lafoensia pacari } \\
\text { St. Hil. }\end{array}$ & Lytharaceae & $\begin{array}{l}\text { Cicatrizante, gastrite e } \\
\text { úlceras, antibiótico }\end{array}$ & Folha & $\begin{array}{l}\text { Compressa, } \\
\text { Decocção }\end{array}$ \\
\hline Para tudo & $\begin{array}{l}\text { Gomphrena } \\
\text { officinalis Mart. }\end{array}$ & Amaranthaceae & Febre, asma, anemia & Raiz & Decocção \\
\hline Pequi, piqui & $\begin{array}{l}\text { Caryocar } \\
\text { brasiliense } \\
\text { Cambess. }\end{array}$ & Caryocaceae & $\begin{array}{l}\text { Afecções das vias } \\
\text { respiratórias }\end{array}$ & Folha & Infusão \\
\hline
\end{tabular}


Tabela 2 . Continuação...

\begin{tabular}{|c|c|c|c|c|c|}
\hline $\begin{array}{c}\text { Nome } \\
\text { Popular }\end{array}$ & $\begin{array}{c}\text { Nome } \\
\text { Científico }\end{array}$ & Família & Indicação Popular & $\begin{array}{c}\text { Parte } \\
\text { Utilizada }\end{array}$ & $\begin{array}{l}\text { Modo de } \\
\text { Uso }\end{array}$ \\
\hline Picão & Bidens pilosa L. & Asteraceae & $\begin{array}{c}\text { Afecções das vias } \\
\text { urinárias, renais e } \\
\text { hepáticas }\end{array}$ & $\begin{array}{l}\text { Ramos, } \\
\text { raiz }\end{array}$ & $\begin{array}{l}\text { Infusão, } \\
\text { decocção }\end{array}$ \\
\hline Planta da seda & $\begin{array}{c}\text { Calotropis procera } \\
\text { (Aiton) W. T. } \\
\text { Aiton }\end{array}$ & Asclepiadaceae & Anti reumática & Folha & Decoção \\
\hline Poejo & $\begin{array}{c}\text { Mentha pulegium } \\
\text { L. }\end{array}$ & Lamiaceae & $\begin{array}{l}\text { Gripe, expectorante, } \\
\text { sinusite }\end{array}$ & $\begin{array}{l}\text { Haste/ } \\
\text { ramos }\end{array}$ & $\begin{array}{l}\text { Infusão, } \\
\text { inalação }\end{array}$ \\
\hline Quebra pedra & $\begin{array}{c}\text { Phyllanthus niruri } \\
\text { L. }\end{array}$ & Euphorbiaceae & Cálculos renais & Toda & Decocção \\
\hline Quebra pedra & $\begin{array}{l}\text { Phyllanthus } \\
\text { tenellus Roxb. }\end{array}$ & Euphorbiaceae & $\begin{array}{l}\text { Cálculos renais, } \\
\text { infecção urinária }\end{array}$ & Toda & Decocção \\
\hline $\begin{array}{l}\text { Quina do } \\
\text { cerrado }\end{array}$ & $\begin{array}{c}\text { Strychnos } \\
\text { pseudoquina A. } \\
\text { St.-Hil. }\end{array}$ & Loganiaceae & $\begin{array}{l}\text { Estimulante do } \\
\text { apetite, cólicas } \\
\text { menstruais }\end{array}$ & Folha & Decocção \\
\hline Quitoco & $\begin{array}{l}\text { Pluchea sagittalis } \\
\text { (Lam.) Cabrera }\end{array}$ & Asteraceae & $\begin{array}{l}\text { Digestive, cólicas } \\
\text { estomacais, ressaca }\end{array}$ & Folha & Suco \\
\hline Romã & $\begin{array}{c}\text { Punica granatum } \\
\text { L. }\end{array}$ & Punicaceae & $\begin{array}{l}\text { Inflamação de } \\
\text { garganta, tosse }\end{array}$ & Fruto & Decocção \\
\hline Rosa branca & Rosa alba L. & Rosaceae & Laxante & Flor & Infusão \\
\hline Rosquinha & & & Gastrite & Raiz & Decocção \\
\hline Sabugueiro & Sambucus nigra L. & Caprifolicaceae & $\begin{array}{c}\text { Gripe, } \\
\text { antiinflamatório, } \\
\text { sinusite }\end{array}$ & Flor, folha & Decocção \\
\hline Salsa & $\begin{array}{c}\text { Petroselinum } \\
\text { crispum (Mill.) A. } \\
\text { W. Hill }\end{array}$ & Apiaceae & Infecção urinária & Toda & Infusão \\
\hline Sangra d'água & $\begin{array}{c}\text { Croton urucurana } \\
\text { Baill. }\end{array}$ & Euphorbiaceae & Cicatrização & Seiva & Compressa \\
\hline São Caetano & $\begin{array}{l}\text { Mormadica } \\
\text { charantia L. }\end{array}$ & Cucurbitaceae & $\begin{array}{l}\text { Cálculos renais, } \\
\text { verminoses }\end{array}$ & Raiz & Decocção \\
\hline $\begin{array}{l}\text { Sucupira, } \\
\text { Sucupira } \\
\text { branca }\end{array}$ & $\begin{array}{l}\text { Pterodon } \\
\text { emarginatus } \\
\text { Vogel }\end{array}$ & Fabaceae & $\begin{array}{c}\text { Inflamação de } \\
\text { garganta, cálculos } \\
\text { renais }\end{array}$ & Semente & $\begin{array}{l}\text { Decocção, } \\
\text { infusão, } \\
\text { alcoolatura }\end{array}$ \\
\hline Tamarindo & $\begin{array}{c}\text { Tamarindus indica } \\
\text { L. }\end{array}$ & Fabaceae & Laxante & Fruto & Suco \\
\hline $\begin{array}{l}\text { Tansagem, } \\
\text { tanchagem }\end{array}$ & $\begin{array}{l}\text { Plantago } \\
\text { australis L. }\end{array}$ & Plantaginaceae & Antiinflamatório & Folha & Suco, infusão \\
\hline
\end{tabular}


Tabela 2 . Continuação...

\begin{tabular}{|c|c|c|c|c|c|}
\hline $\begin{array}{c}\text { Nome } \\
\text { Popular }\end{array}$ & $\begin{array}{c}\text { Nome } \\
\text { Científico }\end{array}$ & Família & Indicação Popular & $\begin{array}{c}\text { Parte } \\
\text { Utilizada }\end{array}$ & $\begin{array}{l}\text { Modo de } \\
\text { Uso }\end{array}$ \\
\hline $\begin{array}{l}\text { Tansagem, } \\
\text { tanchagem }\end{array}$ & Plantago major L. & Plantaginaceae & $\begin{array}{l}\text { Antiinflamatório, } \\
\text { afecções estomacais }\end{array}$ & Folha & Suco, infusão \\
\hline Terramicina & $\begin{array}{c}\text { Alternanthera } \\
\text { brasiliana (L.) } \\
\text { Kuntze }\end{array}$ & Amaranthaceae & Antibiótico & Folha & Infusão, suco \\
\hline Tingui & $\begin{array}{c}\text { Magonia } \\
\text { pubescens St. Hil. }\end{array}$ & Sapindaceae & $\begin{array}{c}\text { Inflamação de } \\
\text { garganta }\end{array}$ & Fruto & Mastigação \\
\hline Valeriana & $\begin{array}{l}\text { Valeriana } \\
\text { officinalis }\end{array}$ & Valerianaceae & Calmante & Folha & Cápsula \\
\hline Velame branco & Macrosiphonia sp. & Apocynaceae & $\begin{array}{l}\text { Depurativo, febre, } \\
\text { expectorante, tosse }\end{array}$ & Folha & $\begin{array}{l}\text { Infusão, } \\
\text { xarope }\end{array}$ \\
\hline Vick & $\begin{array}{c}\text { Mentha arvensis } \\
\text { L. }\end{array}$ & Lamiaceae & $\begin{array}{l}\text { Gripe, tosse, } \\
\text { expectorante, } \\
\text { bronquite }\end{array}$ & Folha & $\begin{array}{l}\text { Infusão, } \\
\text { xarope }\end{array}$ \\
\hline
\end{tabular}

\section{Conclusão}

A população do Buritis - MG, utiliza um grande número de espécies vegetais, principalmente, para fins medicinais. Nesta pesquisa foram levantadas 128 espécies, havendo a possibilidade de haver muitas outras de potencial terapêutico nem conhecidas.

O levantamento etnofarmacológico permitiu verificar que o uso de plantas medicinais no município de Buritis - MG possui tradicionalidade, uma vez que o principal motivo citado para a utilização das plantas medicinais é a tradição familiar (77\%). Na faixa etária acima de 60 anos, $100 \%$ dos entrevistados tinham conhecimento sobre plantas medicinais, no entanto, na faixa etária abaixo de 20 anos, apenas 38\% possuíam esse tipo de conhecimento, apresentando uma preocupante falta de repasse desse tipo de informação para os jovens e evidenciando a importância de se resgatar esse tipo de conhecimento a fim de evitar sua extinção num curto período de tempo.

\section{Referências}

ABRÃO, R. As ervas e a saúde: A farmácia no cerrado. Edição de autor, 2010.

ALMASSY JUNIOR, A. A. Análise das características etnobotânicas e etnofarmacológicas de plantas medicinais na comunidade de Lavras Novas, Ouro Preto/MG. 147p. Tese (doutorado) apresentada ao programa de pós-graduação em Fitotecnia, da Universidade Federal de Viçosa, Viçosa-MG, 2004.
ALMEIDA, N. F. L. et al. Levantamento etnobotânico de plantas medicinais na cidade de Viçosa - MG. Revista Brasileira de Farmácia. v. 90, p. 316 - 320, 2009.

ARNOUS, A. H.; SANTOS, A. S.; BEINNER, R. D. C. Plantas Medicinais de uso caseiro - conhecimento popular e interesse por cultivo comunitário. Revista Espaço para a Saúde. v. 6, p. 1-6, 2005.

Brasil. Farmacopéia Brasileira. Volume 1/ Agência Nacional de Vigilância Sanitária. Brasília: Anvisa, 2010a. 546p., 1v/il. Disponível em: http://www. anvisa.gov.br/farmacopeiabrasileira/index.htm. Acesso em: 20 de setembro de 2011.

BRASIL. Farmacopeia Brasileira. Volume 2 / Agência Nacional de Vigilância Sanitária. Brasília: Anvisa, 2010b. 904p., 2v/il. Disponível em: http://www. anvisa.gov.br/farmacopeiabrasileira/index.htm. Acesso em: 20 de setembro de 2011.

BRASILEIRO, B. G. et al. Plantas medicinais utilizada pela população atendida no programa saúde da família, Governador Valadares, MG, Brasil. Revista Brasileira de Ciências Farmacêuticas. v. 44, p. 629 636, 2008.

CALABRIA, L. et al. Levantamento etnobotânico e etnofarmacológico de plantas medicinais em Indianápolis, Minas Gerais, Brasil. Revista Brasileira de Plantas Medicinais. v. 10, p. 49 - 63, 2008. 
CAMPESATO, V. R. Uso de plantas medicinais durante a gravidez e risco de malformações congênitas. 138p. Tese (doutorado) apresentada ao programa de Pós-graduação em Genética e Biologia Molecular da Universidade Federal do Rio Grande do Sul - UFRS, Porto Alegre, 2005.

CARVALHO, S. F. Estatística básica: teoria e 150 questões. 2 ed. Rio de Janeiro: Elsevier, 2005.

CRESPO, A. B. Recursos Genéticos y Conocimiento Etnofarmacológico Cubanos. Su protección mediante patentes. Boletín Latinoamericano y del Caribe de Plantas Medicinales y Aromáticas. v. 9, n.3, p.153-165, 2010.

CUASSOLO, F.; LADIO, A. \& EZCURRA, C. Aspectos de la comercialización y control de calidad de las plantas medicinales más vendidas en una comunidad urbana del NO de la Patagonia Argentina. Boletín Latinoamericano y del Caribe de Plantas Medicinales y Aromáticas. v. 9, n.3, p. 166 176, 2010.

ELISABETSKY, E. \& SOUZA, G. C. Etnofarmacologia como ferramenta de busca de substâncias ativas. In: Simões CMO, et al. Farmacognosia: da planta ao medicamento. 5ed. Revisada, Porto Alegre/ Florianópolis: Editora da UFSC, p. 107-122, 2004.

FALCÃO, D. Q. \& MENEZES, F. S. Revisão etnofarmacológica e química do gênero Hyptis. Revista Brasileira de Farmácia. v. 84, p. 69 - 74, 2003.

GAMA, M. \& SILVA, M. J. P. A utilização da fitoterapia por idosos de um Centro de Saúde em área central da cidade de São Paulo. Saúde Coletiva. v. 11, p. $79-84,2006$.

IBGE. IBGE Cidades. Disponível em: http://www.ibge. gov.br/cidadesat/topwindow.htm?1. Acesso em 10 fev. 2011.

LORENZI, H. \& MATOS, F. J. A. Plantas medicinais no Brasil: Nativas e Exóticas. Nova Odessa - SP: Ed. Plantarum, 2002.

MACHADO, R. B. et al. Estimativas de perda da área do Cerrado brasileiro. Relatório técnico não publicado. Conservação Internacional, Brasília, DF. Disponível em: <http://conservation.org.br/ arquivos/Relat.DesmatamCerrado.pdf $>$. Acesso em: 10 fev. 2010.

MELO, J. A. Valorização da flora do cerrado com importância medicinal. 34p. Monografia apresentada a Universidade de Brasília - UnB, Brasília, 2011.

MOSCA, V. P. \& LOIOLA, M. I. B. Uso popular de plantas medicinais no Rio Grande do Norte. Revista Caatinga. v. 22, p. 225 - 234, 2009.

OLIVEIRA, F. C. et al. Avanços nas pesquisas etnobotânicas no Brasil. Acta Botanica Brasilica. v. 23, p. $590-605,2009$.

PATWARDHAN, B. Ethnopharmacology and drug discovery. Journal of Ethnopharmacology. v. 100, p. 50-52, 2005.

PEREIRA, Z. V. et al. Levantamento das plantas medicinais do Cerrado Sensu Stricto da Fazenda Paraíso - Dourados, MS. Revistas de Biociências. v. 1, p. $249-251,2007$.

PIRONDO, A. et al. Influencia de factores externos sobre la comercialización de plantas medicinales em um medio urbano: El caso de vendedores criollos e indígenas em Corrientes, Argentina. Boletín Latinoamericano y del Caribe de Plantas Medicinales y Aromáticas. v. 10, p. 553 - 569, 2011.

RODRIGUES, V. E. G. \& CARVALHO, D. A. Levantamento etnobotânico de plantas medicinais no Domínio do Cerrado na região do Alto Rio Grande - Minas Gerais. Ciência e Agrotecnologia. v. 25, p.102-123, 2001.

ROGRIGUES, A. G. \& CASALI, V. W. D. Plantas medicinais, conhecimento popular e etnociência. In: Rodrigues AG, Andrade FMC, Coelho FMG. et al. Plantas Medicinais e aromáticas: etnoecologia e etnofarmacologia. Viçosa: UFV, p. 25 - 76, 2002.

RODRÍGUEZ, F. M. \& ROBINEAU-GERMOSÉN, L. Cuban collaboration with the Program for Applied Research and Diffusion of Medicinal Plants in the Caribbean (TRAMIL). Revista Cubana Plantas Medicinales. v. 14, n.4, 2009.

SACRAMENTO, H. T. Experiência no trabalho fitoterápico. In: plantando e colhendo saúde. 1o Seminário Estadual de Plantas Medicinais. p. 47 50, 1997.

SANO, E. E. et al. Mapeamento semidetalhado do uso da terra do Bioma Cerrado. Pesquisa Agropecuária Brasileira. v. 43, p. 153 - 156, 2008.

SAWYER D. Fluxos de carbono na Amazônia e no Cerrado: um olhar socioecossistêmico. Sociedade e Estado. v. 24, p. 149 - 171, 2009. 
SOUZA, C. D. \& FELFILI, J. M. Uso de plantas medicinais em Alto Paraíso de Goiás, GO, Brasil. Acta Botanica Brasilica. v. 20, p. 135 - 142, 2006.

SOUZA, M. D.; FERNADES, R. R. \& PASA, M. C. Estudo etnobotânico de plantas medicinais na comunidade de São Gonçalo Beira Rio, Cuiabá, MT. Revista Biodiversidade. v. 9, p.91-100, 2010.

VENDRUSCOLO, G. S. \& MENTZ, L. A. Levantamento etnobotânico das plantas medicinais como medicinais por moradores do bairro Ponta Grossa, Porto Alegre, Rio Grande do Sul, Brasil. Acta Botânica Brasilica. v. 20, p. 367 - 382, 2006.

WAYLAND, C. The failure of pharmaceuticals and the power of plants: medicinal discourse as a critique of modernity in the Amazon. Social Science \& Medicine. v. 58, p. 2409 - 2419, 2004. 